\title{
Do supereu antitético ao falo: o lugar da droga em sujeitos neuróticos*1
}

\section{About the superego as an antithetic to the phallus: The place of drugs in neurotic subjects}

Daniela Santos Bezerra*2

Vinicius Anciães Darriba*3

O presente artigo parte da experiência clínica em uma unidade de internação psiquiátrica para homens com diagnóstico de dependentes químicos. Tal experiência foi tomada a partir do que se extrai do discurso do analista (Lacan 1969-70/1992). O agenciamento do objeto a revela que nem sempre a relação com a substância é a causa do sofrimento

*1 O presente artigo é parte inédita da tese de doutorado A clínica psicanalítica no front de guerra às drogas: demanda, identificação e supereu nos equipamentos $A D$, de autoria de Daniela Santos Bezerra e orientação de Vinicius Anciães Darriba, apresentada ao Programa de Pós-Graduação em Psicanálise do Instituto de Psicologia da Universidade do Estado do Rio de Janeiro, com banca de defesa constituída no dia 26 de julho de 2018. A pesquisa teve como base a experiência clínica da autora em dois equipamentos de saúde mental: a Unidade 3 do CIAPS Adauto Botelho, situado em Cuiabá - MT, na qual a autora é membro efetiva da equipe e o CAPS AD III Mirian Makeba, situado no Rio de Janeiro - RJ, no qual a autora se inseriu durante 10 meses, no ano de 2015, para acompanhar a clínica oferecida no espaço coletivo desse serviço. Extraindo consequências das questões que emergiram na clínica articulada à teoria dos discursos de Lacan (1969-70/1992), os autores trabalham neste artigo a proposição de que a relação com a droga não deve ser tomada como causa prévia a uma formação sintomática, bem como articulam clínica e política, resgatando fundamentos da clínica psicanalítica.

*2 Secretaria de Estado de Saúde de Mato Grosso (Cuiabá, MT, Brasil).

${ }^{* 3}$ Universidade do Estado do Rio de Janeiro - UERJ (Rio de Janeiro, RJ, Brasil). 


\section{ARTIGOS}

psíquico. Um dos aspectos presentes nessa clínica, na qual predominam sujeitos neuróticos, é o empuxo à repetição do fracasso, engendrando o sem-sentido. Tal atuação não diz respeito à relação com a droga, mas revela-se modus operandi do sujeito. Apontando a antitese entre falo e supereu, como a única instância que impõe o gozo, estabelecemos a diferença entre o uso da droga como suspensão do gozo fálico como indicado por Lacan (1975/1976) e a repetição compulsiva que exaure o sujeito e realiza o fracasso.

Palavras-chave: Neurose, falo, supereu, droga

Freud (1914/1976d) nos alertara em "Observações sobre o amor transferencial" que "as únicas dificuldades realmente sérias que [os psicanalistas] têm de enfrentar residem no manejo da transferência" ( $p$. 208). Portanto, não é surpreendente que os analistas se mantenham, na contemporaneidade, debruçados sobre esse tema e problematizem os enigmas emergentes no real da experiência analítica. Neste artigo, em que nos voltamos para a dita clínica das toxicomanias, essa experiência será tomada a partir da escrita dos discursos de Jacques Lacan (1969-70/1992) e dos desdobramentos que extraímos do discurso do analista como aquele agenciado pelo objeto $a$. A concepção do discurso do analista como laço social, único que o objeto $a$ agencia, recupera a definição de Lacan da clínica psicanalítica como práxis, mas de modo retrovertido. Ainda no Seminário 11 Lacan (1964/1996b) define a práxis como "uma ação realizada pelo homem, qualquer que ela seja, que o põe em condição de tratar o real pelo simbólico. Que nisto se encontre mais ou menos imaginário tem aqui valor secundário" (p. 14). Desse modo, é o real que agencia aquilo que se seguirá a partir da exortação advertida pelo desejo do analista: um sujeito a ser representado por um significante para outro significante.

A função do significante tomada em trabalho pelo analista, articulada por Lacan no Seminário 17, O avesso da psicanálise (1969-70/1992, p. 65), é demonstrada no matema do discurso do analista como: 


\section{$\frac{a}{S 2} \rightarrow \frac{S}{S 1}$}

Qualquer saber prévio (S2) está abaixo da barra, não serve ao ato analítico, já que esse não se constitui como um aparato teórico-técnico a ser aplicado na experiência analítica.

A construção do objeto $a$ como elemento com o qual se pode operar para tratar dos laços sociais, incluindo o real, nos convém para tratar da transferência, das grandes dificuldades quanto ao manejo, principalmente suas faces de resistência e repetição. Lembrando sempre da advertência lacaniana que nos serve cotidianamente para fazer operar o discurso do analista: "a resistência é sempre do lado do analista" (Lacan, 1958/1998b, p. 601), buscamos não recuar quanto a tais dificuldades.

Atuando em um âmbito clínico referido às chamadas toxicomanias, ${ }^{1} \mathrm{o}$ que podemos extrair que nos serve como norte clínico perante a repetição do fracasso ou a busca ao dano? Diante de múltiplas dores e queixas apresentadas por homens cuja vida é atravessada pelo abuso de substâncias psicoativas, a repetição da cena de fracasso ou humilhação em sujeitos neuróticos chama-nos a atenção e nos coloca a trabalho. Destacamos aqui apenas um dos aspectos presentes nessa clínica, circunscrita institucionalmente como "para dependentes químicos" muito mais por delimitações das políticas públicas de saúde mental, do que, propriamente, pelo rigor da psicanálise. Queremos com isso dizer que, na operação do real pelo simbólico, o sujeito do inconsciente apresenta uma trama singular que coloca em questão seu modo de gozo e suas relações com os objetos. Como psicanalista, não se trata de escutar "a toxicomania", ou "a dependência química", ou "o toxicômano" ou "o dependente químico", mas sim o sujeito. A prerrogativa que nos direciona nessa clínica é a de que nem sempre a relação com a substância se revela a questão mais aguda, mesmo nos casos nos quais a intoxicação orgânica ou a

${ }^{1}$ Clínica desenvolvida em uma unidade de internação psiquiátrica para dependentes químicos de gestão estadual. Fazemos parte de uma equipe multiprofissional, cujo modo de intervenção é livre aos profissionais de nível superior, atendendo às exigências dos conselhos de classe e ao Projeto Terapêutico da unidade. Os projetos terapêuticos singulares são discutidos semanalmente em reunião de estudo de caso. 


\section{ARTIGOS}

busca, acima de qualquer outra coisa, pela substância prevalecem. E por que ela deveria ser?

\section{Por que a ruptura com o gozo fálico?}

Partamos de uma repetida afirmação de Jacques Lacan em "Clotûre aux Journées d'Etudes des Cartels" (1975/1976 p. 268), que doravante identificaremos como Jornada de Cartéis. Encontramos para a droga a significação de operar uma forma de driblar a angústia presente na castração. Lacan falava da importância do caso do "Pequeno Hans" (Freud, 1910/1976b) e do texto "Cinco lições de psicanálise" (Freud, 1910a/1976c) para expor a relação entre a angústia e a descoberta da diferença sexual. Nesse momento de seu ensino, Lacan já havia extraído da elaboração freudiana sobre o complexo de Édipo a primazia do falo simbólico como significante ordenador do inconsciente, bem como mediador da diferença sexual e avançado para dar ao falo o desígnio de um modo de gozo.

Afirma ele:

A angústia é muito precisamente localizada em um ponto na evolução destes pequenos humanos. Este é o momento em que um menino ou uma menina percebe o quê? Percebe que ele se casou com seu pinto (...). Tudo o que permita escapar desse casamento é, obviamente, bem-vindo, daí o sucesso da droga, por exemplo; não há outra definição da droga que esta: é o que permite a ruptura do casamento com o pequeno-pipi. (Lacan, 1975/1976, p. 268; tradução nossa) $)^{2}$

Nesse ponto, portanto, promover a ruptura do casamento com o "pequeno-pipi" é equivalente à noção de ruptura com o gozo fálico. Entretanto, para tratarmos dessa ruptura do casamento com o falo operacionalizada pela droga, primeiramente é necessário situar o lugar dado

${ }^{2}$ Texto original em francês: 'L'angoisse, c'est très précisément localisé en un point de l'évolution de cette vermine humaine, c'est le moment où un petit bonhomme ou une petite future bonne femme s'aperçoit de quoi? S'aperçoit qu'il est marié avec sa queue. [...] tout ce qui permet d'échapper à ce mariage est évidemment le bienvenu, d'où le succès de la drogue, par exemple; il n'y a aucune autre définition de la drogue que celle-ci: c'est ce qui permet de rompre le mariage avec le petit-pipi". 
ao falo no ensino lacaniano, pois, com o avanço do ensino, esse lugar se modifica até chegar à questão do gozo fálico.

A diferença do lugar atribuído ao falo ao longo do ensino não resultou, no entanto, em lugares antagônicos, e o fato de Lacan ter retomado a relação de Hans com seu "pequeno-pipi" em 1975 nos assegura disso. Além disso, a própria forma de tomar a estruturação do inconsciente se redimensiona com o avanço do ensino. Utilizando-se da topologia dos nós no Seminário livro 21, Lacan (1973-74, inédito), promove a patamarização dos registros Real, Simbólico e Imaginário, bem como das estruturas clínicas (neurose, psicose e perversão). Esse é o pano de fundo de como a noção do falo se viu articulada de um ponto ao outro do ensino.

Lacan (1956-57/1995) tomou o falo, primeiramente, no campo do Outro como objeto de desejo da mãe, figurando como sempre em falta. Por isso, sua escrita é em negatividade: $-\varphi$. Subdividindo o complexo de Édipo, o falo significa aquilo que falta à mãe para, em um segundo momento, ser percebido como aquilo que o pai daria ao sujeito. Porém, o que o sujeito recebe é o significante da castração, o falo como falta. O pai é o operador que está, pela lógica, excluído da função que ele mesmo agencia, e só por isso essa função é agenciada como perda. O significante fálico comporta, quanto ao gozo, uma dupla função de perda: proíbe o gozo primordial da mãe e torna impossível o gozo do órgão. O que se ganha com a incidência do falo é a função de significação, ou seja, a ordenação do campo do Simbólico, que veicula o jogo de presença e ausência em consequência da castração. É dessa forma que, ao menos para a neurose, a castração se refere a uma falta decorrente de uma perda primordial, que faz com que o sujeito deseje, colocando a estrutura em movimento, via demanda.

Avançando, já na teoria dos discursos, como um segundo momento de acepção do falo, Lacan criou condições para passarmos da fala à escrita, bem como tratarmos do real como incluído na estrutura. Esta condição do falo como significante responsável por toda significação possível não mudará no ensino de Lacan, o que muda é a escrita da sexuação a partir dos discursos como forma de cernir o gozo. No Seminário livro 18 Lacan (1971/2009), dirá que só o escrito permite estabelecer a verdade do dizer, donde a importância da teoria dos discursos, já que constitui a condição de possibilidade de articulação lógica entre fala, linguagem e escrita. E é nesse momento que a função do falo $\Phi$ será escrita. Em suas palavras:

não há na linguagem outra Bedeutung senão o falo (...) é de ser constituída apenas por uma única Bedeutung que a linguagem extrai 


\section{ARTIGOS}

sua estrutura, a qual consiste em não podermos, pelo fato de habitá-la, utilizá-la senão por metáfora. (p. 139)

Quando Lacan (1971-72/2012) elabora a tábua da sexuação, ou seja, a escrita lógica da diferença sexual, coloca a função do falo no lado masculino.

Tábua da sexuação

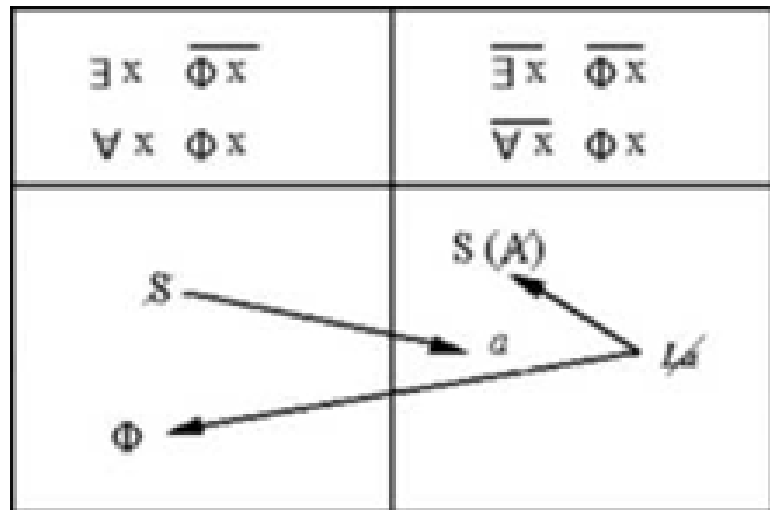

Porém, é a esse significante que o lado feminino se dirige e se refere, enquanto o masculino se dirige ao objeto $a$, estando casado com seu falo. Mesmo assim, o falo não é "conciliador" para os dois lados, sua própria função é fazer obstáculo à relação sexual porque é o que atesta a castração e a não complementaridade entre os sexos.

No Seminário livro 20, Lacan (1972-73/1985b) retoma, ao tratar da lógica da sexuação, a função fálica como aquela cuja necessidade "se revela ser apenas uma mera contingência" (p. 127). Ou seja, a diferença entre neurose e psicose deixa de ser o déficit do Nome-do-Pai como operador da função fálica, que, como contingencial, poderá comparecer ou não no lugar daquilo que sustenta ou estabiliza a estruturação inconsciente. Lacan inicia, então, o avanço da linguagem à escrita e dá uma nova interpretação ao modo de operação do falo nas dimensões simbólico, real e imaginário, cujas consequências se referem à sexuação, à estruturação e à formação do sintoma. É a inscrição da castração e do recalque que está aqui em jogo, definindo se a estrutura responde à falta do Outro como neurótica, psicótica ou perversa. Se o falo operar aí como resultado da operação da metáfora paterna, estrutura-se uma neurose. 
A partir dos anos 1970, no ensino lacaniano o Nome-do-Pai, como operador da metáfora paterna, passou a ser um operador dentre vários, ou seja, passa a ser contingencial na estruturação. Era a metáfora paterna e o significante fálico que capitaneavam a forma paradigmática de estruturação, que no período do Seminário livro 3 (Lacan, 1955-56/1985a) era tomado como única garantia de entrada do sujeito na linguagem e de sua subordinação à Lei. Esse paradigma fazia com que a acepção da estrutura psicótica fosse tomada como deficitária do falo como operador. No final do ensino lacaniano, o falo permanece como índice da falta no Outro. Contudo, esse índice pode ser ocupado por outras formas de sustentação ou suplência da falta no Outro. A ideia de Nome-do-Pai vai perdendo seu vigor ou sua potência simbólica ordenadora para ceder lugar à pluralidade de soluções que recorrem a diferentes artifícios. Portanto, a metáfora paterna, como correlata à operação do recalque, é apenas a operação que resulta na neurose, mas não é mais a operação por excelência. Lacan (1975-76/2007) nos deixa essa contribuição como um dos grandes legados para a prática clínica.

A chamada pluralização do Nome-do-Pai, demonstrada a partir do nó borromeano, ${ }^{3}$ possibilita a apreensão de que o que sustenta uma estrutura é a invenção, para além de uma operação metafórica (fálica), que resulta em uma nodulação operada de forma singular. O Nome-do-Pai, portanto, não é mais normatizador da forma de estruturar-se, havendo, assim, uma equivalência entre ele e qualquer outra coisa que sirva para fazer suplência à falta no Outro. Assim como o falo não é o único operador capaz de fazer suplência à falta no Outro. A topologia dos nós, da qual Lacan se utilizou para mostrar o real articulando-o, no momento vivo de sua elaboração, aos registros simbólico e imaginário, situa de forma patamarizada os registros e possibilita pensar as formas de estruturas clínicas, tirando a psicose do lugar de deficitária. Nessa topologia, visualizamos o nó borromeano de quatro elementos com reforço no simbólico ( $\Sigma$ ) em cinza (Lacan, 1975-76/2007, p. 21).

${ }^{3}$ Durante o Seminário livro 20, Lacan retoma o nó borromeano por meio da topologia, utilizando-se de três cordinhas de barbantes, cujas pontas se unem, formando 3 círculos, para uni-las de modo que desatando uma delas, as três se soltam. Cada rodela de barbante representa os três registros: Real, Simbólico e Imaginário. Os três registros, portanto, estão unidos figurando, topologicamente a estrutura, de modo que, caso um se rompa, a estrutura toda se esvai. 


\section{ARTIGOS}

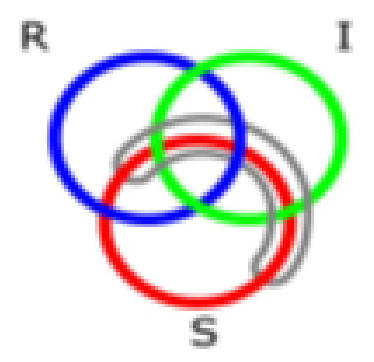

A suplência à falta no Outro tem a função de ser uma resposta que estrutura, para o sujeito, sua realidade psíquica. Tal suplência, Lacan chamará de sinthoma, como o quarto elo, em cinza, aquilo que sustenta a estrutura e lhe confere a lógica neurótica, ou psicótica ou perversa. Portanto, é o sinthoma que define a estrutura clínica, cujo estatuto é diferente do sintoma (sem a letra "H") como realização da pulsão e resultado do recalque. Uma vez ocorrida a incidência da suplência à falta no Outro, o sinthoma nodula a estrutura, e este quarto elo não será posteriormente passível de troca. Cada ser falante deve, portanto, inventar sua própria maneira de suplenciar a falta no Outro. O falo, por sua vez, ganha estatuto de atributo de um dos modos de gozo, ou, em outras palavras, nomeia o gozo fálico $\left(\mathrm{J}(\Phi)^{4}\right.$. Portanto, se o gozo fálico é apenas um dos modos de gozo, o ser falante tem notícia de diferentes modos de gozo que não somente aquele referenciado pelo falo. É com esses elementos do ensino que Lacan (1975/1976) na Jornada de Cartéis refere-se à função da droga.

Chama-nos a atenção que tal afirmação de Lacan esteja bastante de acordo à que Freud (1915/1976e) faz em "Luto e melancolia". Sem se ocupar diretamente dos alcoolistas, Freud descreve que ocorre na mania o mesmo que na "embriaguez alcoólica": a suspensão do recalque (traduzido na edição abaixo como repressão). Diz ele:

A embriaguez alcoólica, que pertence à mesma classe de estados [maníacos], pode (na medida em que é de exaltação) ser explicada da mesma maneira; aqui, provavelmente, ocorre uma suspensão, produzida por toxinas, de

${ }^{4} \mathrm{~J}=$ jouissance e $\Phi=$ Falo 
dispêndios de energia na repressão. A opinião popular gosta de presumir que uma pessoa num estado maníaco desse tipo se deleita no movimento e na ação porque ela é muito "alegre". Naturalmente, essa falsa conexão deve ser corrigida. (p. 287)

Freud postulava ali uma função, ainda não destacada como instância tópica, de conjunção entre consciência moral e ideal do eu, a qual o álcool suspenderia, proporcionando a desinibição de energias antes reprimidas. A própria definição de ideal do eu só seria definitivamente vislumbrada anos depois no "Psicologia de grupo e análise do ego" (Freud, 1921/1976h). O ideal do eu representa a medida do que o eu deve realizar para ser amado, ou seja, para contentar-se consigo mesmo. Em outras palavras, para recuperar o contentamento que experimentava no narcisismo primário, o eu deve espelhar-se nesse ideal.

Com Lacan o recalque é tomado como a operação da neurose para lidar com a castração. A ação de suspensão do recalque proposta por Freud (1915/1976e), em "Luto e melancolia", exercida pela embriaguez coaduna-se com a ruptura com o casamento com o "pequeno-pipi". Se a suspensão é eficaz para lidar com a angústia, o rompimento da mediação simbólica, contudo, é pontual e não definitivo. A divisão originária da constituição subjetiva permanece intacta e o mal-estar permanece ali, exigindo o trabalho constante do sujeito, permanecendo no laço social. Desde Freud sabemos que tal suspensão faz parte do pacto civilizatório e não é similar à compulsão por algum objeto. Nesse sentido, nossa clínica aponta para uma operação que não prioriza a suspensão do gozo fálico como foco.

Avançamos sobre o que traziam os homens por nós escutados, a saber, um empuxo à repetição incessante que parece vir do nada, positivada e inquestionada em direção ao fracasso/flagelo. Um importante modo de atuação que engendra o sem-sentido que captura o sujeito neurótico como se ele nada tivesse a ver com isso. Tal atuação não diz respeito somente à relação com a droga, mas revela-se presente no modus operandi comum do sujeito, antes mesmo de qualquer uso de substâncias psicoativas. Obviamente este modus operandi pode aparecer na forma de identificação ao estigma de criminoso ou culpado ou fracassado, mas o mais enigmático é a falta de significação para esse empuxo a estragar o que está dando certo ou a colocar-se em cenas de autoflagelo. Que tipo de operação seria esta? 


\section{ARTIGOS}

\section{Falo e supereu como antitéticos}

Vejamos, assim, como se articula esse perder o limite, que se repete na clínica, levando o sujeito a se expor repetidamente a uma cena de fracasso ou humilhação e à tentativa de lidar com o embaraço da diferença sexual suspendendo o recalque por meio de instrumentos disponíveis na civilização. Seguindo a pista do que também intrigou Freud (1916/1976f) no artigo "Alguns tipos de caráter encontrados no trabalho psicanalítico", no item "Arruinados pelo êxito" encontramos os fundamentos do supereu como instância nas origens da deflagração de um padecimento logo em seguida à realização de uma conquista aparentemente desejada. Freud toma tais fenômenos a partir do mesmo fundamento da resistência ao tratamento que aparece como parte do caráter do paciente, nem sempre reconhecidos por ele próprio. Esses fenômenos nada teriam a ver com os sintomas constituídos da maneira metafórica.

A partir dos casos descritos, Freud (1916/1976f) comenta:

[...] É como se elas não fossem capazes de tolerar sua felicidade, pois não pode haver dúvida de que existe uma ligação causal entre seu êxito e o fato de adoecerem. [...] Constitui tarefa difícil, contudo, descobrir a essência e a origem dessas tendências julgadoras e punitivas [...]. (p. 357)

E, ao final do texto, conclui:

O trabalho psicanalítico nos ensina que as forças da consciência moral que induzem à doença em consequência do êxito, e não, como normalmente, em consequência da frustração, se acham intimamente relacionadas com o complexo de Édipo, a relação com o pai e a mãe, como talvez o faz nossa consciência de culpa em geral. (p. 357)

Apesar de citar a consciência moral e a culpa em geral, não está esclarecida a forma pela qual esses fenômenos se originam, visto que a formulação sobre a pulsão de morte só terá sido constituída em 1920 no texto "Além do princípio de prazer", bem como a formulação sobre o supereu só terá ocorrido no texto "O eu e o id" (Freud, 1923/2007a).

A obtenção de prazer na dor (não somente no ato sexual) torna-se explicável por Freud a partir da necessidade de satisfação da pulsão de morte. A "força demoníaca" descrita por Freud (1920/2006) diz respeito a uma forma de compulsão que ocorre à revelia da produção ou não de sintomas. Vejamos:

A impressão que dão é de serem perseguidas por um destino maligno ou possuídas por algum poder "demoníaco"; a compulsão que aqui se 
acha em evidência não difere em nada da compulsão à repetição que encontramos nos neuróticos, ainda que as pessoas que agora estamos considerando nunca tenham mostrado quaisquer sinais de lidarem com um conflito neurótico pela produção de sintomas. (p. 35)

Freud, portanto, descreve a compulsão à repetição como aquilo que sobrepuja o princípio do prazer e ainda está na origem dos sonhos de angústia e das brincadeiras infantis, contudo não têm a mesma constituição dos sintomas. Antes do delineamento do supereu ou de posições subjetivas masoquistas (Freud, 1924/2007b), Freud descreve a satisfação da pulsão de morte como necessidade do sujeito em assenhorear-se de uma cena traumática ou na qual sente-se dominado como objeto.

A partir da segunda tópica de sua teoria, Freud (1923/2007a) define em primeira mão o Supereu (Über Ich). Nele, Freud diferencia eu e supereu descrevendo a origem de ambos na escuta de "restos de palavras", de "representações verbais" pré-conscientes, sendo que, porém, ao supereu acrescem-se "fontes situadas no Id" (p. 60):

Coloca-se então a questão de se saber em que consiste, afinal, o supereu.

Levando em conta a importância que havíamos atribuído aos restos-de-palavras pré-conscientes no Eu, será que - talvez por ser Ics - o supereu consiste exatamente dessas imagens-de-palavra [Wortvorstellungen]? Ou se trata de outra coisa? Nossa resposta será modesta e reside apenas em dizer que é impossível ao supereu renegar que também sua origem se situa naquilo que já foi um dia escutado. (p. 60)

A importância da origem do supereu a partir daquilo que se ouve será retomada por Lacan (1962-63/2005a) na medida em que ele elabora uma das facetas do objeto $a$ como voz. O supereu, portanto, é portador de marcas inscritas pela via simbólica acrescido de uma urgência daquilo que, por não se inscrever e permanecer como rebotalho, impõe-se. O paradoxo dessa instância psíquica resulta em suas diferentes formas de manifestação.

Freud (1923/2007a) atribui ao supereu uma ordem contraditória dada ao sujeito: que ele seja como o pai, ao mesmo tempo que reforça que o sujeito não tem as mesmas prerrogativas que o pai para realizar seus desejos. Instaura-se um imperativo paradoxal, tomado por Freud para explicar o ganho secundário com a satisfação na culpa. Um excesso e uma repetição constituem um gozo vinculado ao castigo que se repete. Porém, o sujeito não se sente culpado, apenas repete o sofrimento sem saber por que. O supereu torna-se, assim, a instância veiculadora da pulsão de morte que não se ligou a nenhum sintoma. 


\section{ARTIGOS}

Em "Problema econômico do masoquismo" as elaborações de Freud (1924/2007b) permitem compreender que a pulsão de morte inicialmente está amalgamada à pulsão de vida ou libido, sendo que, posteriormente, uma parte dessa pulsão de morte se desprende e vincula-se ao supereu, que passa a ser veículo dela. É no masoquismo primário que se ancoram as demais formas de satisfação das pulsões, sendo a dor e o prazer alvos ou objetivos a serem atingidos e não somente a satisfação de sensações internas (Freud, 1924/2007b). Dessa forma, corrobora-se a nova teoria das pulsões de 1920: prazer e desprazer não podem mais ser explicados pelo aumento ou diminuição de tensão, são objetivos a serem alcançados independentemente da necessidade orgânica. Já no masoquismo moral, há a imposição ao sujeito de uma punição, que vai além do sentimento de culpa. Tal requinte paradoxal nada mais é do que a exigência de satisfação agenciada pelo supereu, que busca o sofrimento como finalidade.

No texto "O mal-estar na civilização" Freud (1930/1976j) reforça o caráter sem sentido do funcionamento do supereu. Essa instância serve de apoio à consciência moral, mas ela nada tem a ver com suas exigências; quanto mais se dá, mais ele cobra. Ao supereu cabe ser "representante de todas as restrições morais, o advogado de um esforço tendente à perfeição" (Freud, 1933/1976j, p. 72), como também suas origens devem ser buscadas na primeira forma de identificação: direta e imediata, antes de qualquer investimento em objeto; identificação ao pai de sua pré-história pessoal (Freud, 1923/2007a).

Novamente encontramos a comparação feita por Freud (1930/1976j) dos estados maníacos à função da intoxicação:

É possível que haja substâncias na química de nossos próprios corpos que apresentem efeitos semelhantes, pois conhecemos pelo menos um estado patológico, a mania, no qual uma condição semelhante à intoxicação surge sem administração de qualquer droga intoxicante [...] sabe-se que, com o auxílio desse "amortecedor de preocupações", é possível, em qualquer ocasião, afastar-se da pressão da realidade e encontrar refúgio num mundo próprio, com melhores condições de sensibilidade. (p. 97)

$\mathrm{Na}$ analogia feita por Freud (1915/1976e) da embriaguez com os estados de mania, a suspensão da mediação fálica acabaria descrevendo um triunfo do eu sobre o supereu. Porém, o que encontramos na clínica como sofrimento psíquico não equivale a um deleite, mas revela-se como a imposição feroz da perda de limites até a exaustão. Assim também nos parece possível utilizar a comparação feita por Freud (1930/1976j, p. 97) entre os estados maníacos 
à intoxicação ou entorpecência, para afirmar, na mesma medida, que tais fenômenos clínicos não triunfam sobre o supereu, mas sim atualizam exatamente a subjugação à instância superegoica. É por isso que necessitamos da elaboração lacaniana sobre o supereu para abordar o paradoxo que se apresenta na clínica.

Segundo Gerez-Ambertín (2003), não é possível encontrar formulação teórica definitiva do supereu no ensino lacaniano, a ponto de Lacan (1971/2009) declarar que "a única coisa que nunca tratei é do supereu" (p. 84). Não obstante, durante todo o ensino Lacan delineia o Supereu claramente não como instância proibidora, ou como somente herdeira do Édipo. Se, para Freud, o supereu é ligado ao ideal do eu por identificação ao pai da pré-história, que faz o sujeito incorporar a voz da perfeição, para Lacan essa voz do Outro primordial é não toda herdada do pai. O que é transmitido do pai, nesse caso, são justamente as falhas e não a perfeição. No Seminário livro 3 Lacan (1955-56/1985a) situa que "é o discurso do meu pai, por exemplo, na medida em que meu pai cometeu faltas as quais estou absolutamente condenado a reproduzir - é o que se denomina superego" (p. 118).

Logo no Seminário 1, Lacan (1953-54/1996a) examinou a questão do 210 supereu como um imperativo, diferenciando-o do ideal do eu e enfatizando "seu caráter insensato, cego, de puro imperativo, de simples tirania" (p. 123), para todo e qualquer sujeito. Segue afirmando que o supereu chega a ser o próprio desconhecimento da lei:

O supereu é, a um só tempo, a lei e sua destruição. Nisso ele é a palavra mesma, o comando da lei, na medida em que dela não resta mais do que a raiz. A lei se reduz inteiramente a alguma coisa que não se pode nem mesmo exprimir, como o Tu deves, que é uma palavra privada de todos os seus sentidos. É nesse sentido que o supereu acaba por se identificar àquilo que há somente de mais devastador, de mais fascinante, nas experiências primitivas do sujeito. (p. 123)

Lacan revela que o supereu, portanto, é o resíduo que escapa à articulação entre desejo e lei do Édipo ou, em outras palavras, a residuação do pai que faz exceção à norma fálica. Ainda em Freud é possível reconhecer a concepção do supereu como instância, acima de tudo, sob a perspectiva da incidência da pulsão de morte sobre o eu. Portanto, é possível dizer que, apesar de ser derivado da operação da metáfora paterna, assim como o falo, o Supereu herda aquele resto de operação que faz contraponto a ela mesma.

É tratando justamente das relações de objeto que Lacan (1956-57/1995) define a origem do supereu como anterior à inscrição do significante 


\section{ARTIGOS}

Nome-do-Pai, tendo relação com a passagem de um suposto objeto real da necessidade, pela via da simbolização. Ele surge no lugar da recusa do dom do amor. Os resquícios daquilo que se ouve, como disse Freud (1923/2007a), ganham corpo, compensando a falta do dom do amor e preenchem o desamparo, fazendo companhia ao sujeito. A origem do supereu, portanto, está no desamparo primordial vivido pelo sujeito. É nesse desamparo que algo se funda, catalisando e dando vetorização à pulsão de morte. Nas palavras de Lacan (1956-57/1995):

[...] um objeto real assume sua função como parte do objeto de amor, assume sua significação como simbólico, e a pulsão se dirige ao objeto real como parte do objeto simbólico; este se torna, como objeto real, uma parte do objeto simbólico. [Se isto pode ocorrer] [...] qualquer outro objeto capaz de satisfazer uma necessidade real pode vir colocar-se em seu lugar, e, principalmente, este objeto já simbolizado [...] que é a palavra. Na medida em que a regressão oral ao objeto primitivo de devoração vem compensar a frustração de amor, essa reação de incorporação dá seu modelo [...] à incorporação de certas palavras dentre outras, que está na origem da formação precoce daquilo a que se chama o supereu. (p. 178)

A voz do Outro primordial é amoral, ela apenas agencia a pulsão de morte que impõe somente uma ordem: goze! Não importa se o sujeito goza obedecendo à lei ou transgredindo-a, importa que ele goze sem mediação. $\mathrm{O}$ exemplo clínico mais corriqueiro quando se trabalha nos equipamentos de saúde mental, é o retorno da voz do Real ao psicótico. No caso dos neuróticos que só podem ouvir "a voz da consciência", o açoite do supereu se converte em atuação mortífera incessante, como correlato da castração, impelindo o sujeito ao gozo.

Assim, se a completude nas relações é impossível, também é impossível o gozo absoluto ou a satisfação total das pulsões. Não à toa, Freud desde 1905 (1976a) diria que a satisfação das pulsões é sempre parcial. É nesse ponto que se encontra a insensatez da ordem superegoica, na medida em que passa a exigir que o sujeito goze "até o fim" a qualquer custo.

Em "Subversão do sujeito e dialética do desejo no inconsciente freudiano" encontramos a descrição da castração como reguladora do gozo, já que a cadeia significante "em si não barra o acesso do sujeito ao gozo; ela apenas faz de uma barreira natural um sujeito barrado. Pois é o prazer que introduz no gozo seus limites..." (Lacan, 1960/1998c, p. 836). E o que há no prazer humano que limita o gozo? Segundo Lacan, a resposta só pode advir do fato de a castração envolver um sacrifício do falo. Isto é: "é a simples indicação desse gozo em sua infinitude que comporta a marca de sua 
proibição e, para constituir essa marca, implica um sacrifício: o que cabe num único e mesmo ato, com a escolha de seu símbolo, o falo" (p. 837).

O falo regula o gozo, enquanto o supereu se constitui justo como o imperativo do gozo. Razão pela qual podemos dizer que falo e supereu são antitéticos. De acordo com Gerez-Ambertín (2003), "o supereu é o avesso do desejo, é a patogenia da lei, é sua falha estrutural”' (p. 221).

Lacan (1962-63/2005a), no Seminário livro 10, elabora um grande marco conceitual de seu ensino: o objeto $a$ disjunto do significante. Nesse Seminário a voz é tomada como uma das cinco formas do objeto a (seio, fezes, falo, olhar e voz), avançando para além do modo freudiano de tomar a relação de objeto. O objeto $a$ é aquilo que não pode ser especularizado, não tem sentido, não tem consistência, senão como furo, ao qual as cinco formas de caracterização the fazem borda. Em sua dimensão real, e não simbólica, a voz veicula uma sonoridade impossibilitada ao significante. A partir dessa elaboração, Lacan recorre à homofonia da língua francesa para transmitir que, ao ouvir o mandamento superegoico "Goza!" (Jouis!), o sujeito obedece com "Ouço" (J'oü̈s) (Lacan, 1962-63/2005a, p. 91). O supereu, portanto, é a instância que encarna tal voz, imperativa e sem sentido algum. Resíduo mortífero que investe contra o sujeito independente de ele passar pelo Édipo ou não (Pena, 2011, p. 18), ou seja, não se limita à estrutura neurótica.

Já no Seminário livro 18, Lacan (1971/2009), desvela a relação entre o pai primevo e o supereu, justificando, portanto, a ordem de busca pelo gozo puro:

Qual é a essência do supereu? [...] Qual é a precisão do supereu? Ele se origina precisamente nesse Pai original mais do que místico, nesse apelo como tal ao gozo puro, isto é, à não castração. Com efeito, que diz esse pai no declínio do Édipo? Ele diz o que o supereu diz. Não é à toa que não o abordei realmente até agora. O que o supereu diz é: Goza! (p. 166)

É essa ordem, a ordem impossível de satisfazer, e que está, como tal, na origem de tudo o que se elabora sob o termo "consciência moral", por mais paradoxal que isso lhes possa parecer.

Finalmente, no Seminário livro 20, o gozo fálico, apontado por Lacan (1972-73/1985b, p. 17) como gozo ao redor do qual "tudo gira", associa-se à dupla função de perda do significante fálico: proíbe o gozo primordial da mãe e torna impossível o gozo do órgão. Mesmo sendo a única possibilidade de mediação simbólica, é a própria função do falo o que faz obstáculo à complementaridade entre os sexos, ou seja, não dá acesso ao corpo do Outro como Outro sexo. Nas palavras de Lacan, "o gozo enquanto sexual é 
fálico, quer dizer, não se relaciona ao Outro como tal" (p. 18). O gozo fálico, portanto, não leva o sujeito de seu gozo, homem, ao Outro, mulher, mas sim produz efeitos como o significante, o objeto, a fantasia. Não promove a complementaridade entre os sexos, mas possibilita a relação do ser falante com seus objetos, que não é sem embaraço.

Desta forma, se a mediação fálica é um instrumento de negociação ou um modo de estar no mundo apaziguando a incidência da angústia correlata à Lei paterna, o supereu faz empuxo ao gozo infinito fora da lei. Justamente pela não complementaridade nas relações, o supereu impõe uma ordem que só "se promove pela infinitude" (Lacan, 1972-73/1985b, p. 11). Portanto, na perspectiva lacaniana o supereu tem função antitética à lógica fálica (reguladora do gozo) e impele à perda de limites quanto ao gozo. Se o falo, então, é aquilo que faz obstáculo à complementaridade dos sexos, o supereu é a instância que tenta burlar a mediação fálica e impõe o gozo em sua forma de "infinitude".

Assim, o funcionamento do supereu independe do encontro do sujeito com o efeito de uma substância psicoativa e qualquer objeto pode ocupar o lugar de veiculador de um gozo sem limites: trabalho, jogo, amor, religião, alimento e quaisquer outros ao alcance desse indivíduo. A razão ou o sentido no contexto histórico particular no qual o sujeito pode situar que lugar ocupa esse objeto, pode estar na persistência de um autoboicote, na autoflagelação em apelo ao Outro, no prazer com o autoflagelo, na fuga de uma dor não simbolizada e, por isso, desconhecida; enfim, em modos próprios de veicular a pulsão de morte. O empenho desses homens na realização dessa imposição ao fracasso, a qual eles só se questionam a posteriori, considerando-a cruel e independente deles, ou da posição de devedores e não merecedores, é maior e mais eficiente que qualquer outra realização do sujeito. A força avassaladora ou demoníaca que os impele para o fracasso parece vir de fora e não de um mecanismo de autoboicote. Em alguns casos, aparece só depois outra cruel imposição, como uma grande dose de autojulgamento, arrependimento e exposição de si mesmo a um cenário de humilhação/flagelação. Já em outros, a cena de humilhação e fracasso se alterna com um brio excessivo, ou com provocação ao outro para que o julgue ou o reconheça e a qualquer gesto ou palavra não congruente com esse brio, impõe-se a necessidade do fracasso como forma de agredir o outro semelhante.

Afirmamos, por fim, que a compulsão por uma substância psicoativa, para além da referência ao tratamento do mal-estar ou do embaraço da não complementaridade, pode surgir, como vemos em nossa clínica, associado à imposição de um gozo sem limites. E supomos que o mesmo modo de gozo tirânico possa operar em outras. Apontamos, assim que se faz necessário 
diferenciar o uso da droga como ruptura contingencial e parte do pacto civilizatório, como parte do manejo do mal-estar e do embaraço, maior ou menor, que é consequência da castração. Essa ruptura contingencial não seria, por si só, problemática ou compulsiva. O que se problematiza é o sofrimento psíquico causado por uma compulsão que se associa a uma busca ao dano, que antes de ser função da droga, revela-se como função do supereu.

Apostando que a clínica psicanalítica ainda não esgotou as possibilidades de intervenção quanto à neurose no espaço coletivo, trazemos a declaração de Lacan (1973/2003c) feita à TV italiana: "a gulodice pela qual Freud denotou o supereu é estrutural — não é um efeito da civilização [...]" (p. 528). Essa declaração corrobora nossa experiência clínica, em detrimento do que poderia se tomar por uma suposta mudança de constituição do inconsciente na atualidade. Somente ao ocuparmos o lugar do analista é possível depurar aquilo que é trazido pelos pacientes, tentando levar às últimas consequências o rigor do método freudiano.

\section{Conclusão}

Três anos antes da Jornada de Cartéis, Lacan (1972-73/1985b) indicara o supereu como correlato à castração, "signo com que se paramenta a confissão de que o gozo do corpo do Outro só se promove pela infinitude" (p. 11).

O fato de desatrelarmos a compulsão como atuação imposta pelo supereu da droga como objeto não é sinônimo de que estamos banalizando o sofrimento psíquico daqueles que buscam tratamento sob a égide da toxicomania ou da dependência química. Sem dúvida há sofrimento psíquico, mas enfatizamos que este não é necessariamente originado pela relação com a droga. O que verificamos com nossa clínica é que a compulsão está, sim, atrelada à obediência ao imperativo de gozo, função comandada pela instância do supereu. Não estamos, com isso, discordando do dito lacaniano na Jornada de Cartéis (1975/1976); estamos, sim, especificando a diferença entre o uso de um instrumento incluído no laço social para suspenção do gozo fálico e a repetição compulsiva que exaure o sujeito e o coloca em situação de humilhação. Nesse sentido é que definimos o supereu como antitético ao falo, sendo este o elemento que media e norteia o gozo, enquanto a instância superegoica suspende essa mediação.

Nossa proposição não se coaduna com uma higienização ou um savoirfaire dos corpos (Lacan, 1972/2003b), tampouco com a proposta de que se 


\section{ARTIGOS}

domine sua natureza pulsional. Nossa aposta é de que a intervenção do analista se dirija à possibilidade do sujeito se apropriar de seu desejo, o que deve trazer consequências em sua forma de lidar com seu corpo, com seu gozo.

O padecimento estrutural a partir da "gulodice" do supereu, que se inscreve singularmente no coletivo de acordo com a configuração do laço social possível em cada época, nos remete à condução imaginada por Freud (1919/1976g, p. 181) em "Linhas de progresso na terapia psicanalítica". Freud supõe que o Estado deverá fornecer tratamento público à coletividade:

de modo que homens que de outra forma cederiam à bebida, mulheres que praticamente sucumbiriam ao seu fardo de privações, crianças para as quais não existe escolha a não ser o embrutecimento ou a neurose, possam tornar-se capazes, pela análise, de resistência e de trabalho eficiente. (p. 181; grifo nosso)

A questão se desdobra na constatação de que há um sofrimento que se mantém na atualidade sem lugar para ser tratado, na medida em que presenciamos há alguns anos o desmonte da Reforma Psiquiátrica Brasileira. A proliferação de ofertas de "tratamento" que buscam homogeneizar e padronizar pessoas não operaria o mesmo mecanismo de alimentar a culpa, que é uma das faces do supereu? Desde os grupos de autoajuda, o tratamento em internação compulsória, até as comunidades terapêuticas de cunho religioso, há uma busca de inclusão das pessoas em um discurso totalitário no qual todos se unem em torno da imposição da abstinência e do reforço à culpa, em desprezo a qualquer singularidade.

O saber totalitário como agenciamento de discurso dirige-se justamente ao objeto a como produtor de novos sujeitos descartáveis ao laço social.

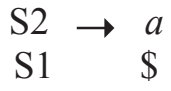

Discurso Universitário

Se o supereu, originário do objeto $a$ voz, é essa instância que prega a peça do autoboicote, encontrará no Discurso Universitário também designado por Lacan (1969-70/1992) como o discurso totalitarista, a fonte para exercer a tirania que condena o ser falante sempre que este padeça de algo diferente do que é preconizado como o bem. Vê-se aí um terreno fértil para que o supereu, reforçado pela identificação opressora, gere um novo mecanismo de autoboicote cego e desresponsabilizado, incessantemente. 
Em tempos de protofascismo e do triunfo da religião, previsto por Jacques Lacan (1974/2005b), ressaltamos a importância de divulgar o que a clínica dá a ver que contribuam para o debate sobre a intervenção no sofrimento psíquico. Para que ele saia do moralismo e do obscurantismo e que as propostas de intervenção não estejam pautadas em um ideal inalcançável de bem-estar padronizado.

Para além das chamadas toxicomanias e da tentativa de gozar sem limites mesmo que atualizando um fracasso, é preciso reintroduzir a questão do gozo no laço social, fazendo girar os discursos. Eis o principal viés de intervenção do discurso do analista. A intervenção do analista quanto ao modo como o sujeito experimenta o gozo, deve levá-lo a percorrer uma modificação de posição de tal forma que ele deixe de se manter na impotência e passe a lidar com a impossibilidade. Já a relação com a substância, ainda que abusiva, não pode ser tomada na ontologia do discurso do analista, pois o trabalho do psicanalista, sabendo que sua postura não é de ordem técnica, dirige-se ao estatuto do Inconsciente, que longe de ser ôntico, é ético (Lacan, 1964/1996b).

\section{Referências}

Freud, S. (1976a). Fragmento da análise de um caso de histeria (Vol. VII). In Edição Standard Brasileira das Obras Psicológicas Completas de Sigmund Freud. Rio de Janeiro, RJ: Imago. (Trabalho original publicado em 1905).

Freud, S. (1976b). Análise de uma fobia de um menino de cinco anos (Vol. X). In Edição Standard Brasileira das Obras Psicológicas Completas de Sigmund Freud. Rio de Janeiro, RJ: Imago. (Trabalho original publicado em 1910).

Freud, S. (1976c). Cinco lições de psicanálise (Vol. XI). In Edição Standard Brasileira das Obras Psicológicas Completas de Sigmund Freud. Rio de Janeiro, RJ: Imago. (Trabalho original publicado em 1910).

Freud, S. (1976d). Observações sobre o amor transferencial (Vol. XII). In Edição Standard Brasileira das Obras Psicológicas Completas de Sigmund Freud. Rio de Janeiro, RJ: Imago. (Trabalho original publicado em 1914-15).

Freud, S. (1976e). Luto e melancolia (Vol. XIV). In Edição Standard Brasileira das Obras Psicológicas Completas de Sigmund Freud. Rio de Janeiro, RJ: Imago. (Trabalho original publicado em 1915).

Freud, S. (1976f). Alguns tipos de caráter encontrados no trabalho psicanalítico (Vol. XIV). In Edição Standard Brasileira das Obras Psicológicas Completas de Sigmund Freud. Rio de Janeiro, RJ: Imago. (Trabalho original publicado em 1916). 


\section{ARTIGOS}

Freud, S. (1976g). Linhas de progresso na terapia psicanalítica (Vol. XVII). In Edição Standard Brasileira das Obras Psicológicas Completas de Sigmund Freud. Rio de Janeiro, RJ: Imago. (Trabalho original publicado em 1919).

Freud, S. (1976h). Psicologia de grupo e análise do ego (Vol. XVIII). In Edição Standard Brasileira das Obras Psicológicas Completas de Sigmund Freud. Rio de Janeiro, RJ: Imago. (Trabalho original publicado em 1921).

Freud, S. (1976i). O mal-estar na civilização (Vol. XXI). In Edição Standard Brasileira das Obras Psicológicas Completas de Sigmund Freud. Rio de Janeiro, RJ: Imago. (Trabalho original publicado em 1930).

Freud, S. (1976j). Novas Conferências Introdutórias sobre Psicanálise, Conferência XXXII, 'Ansiedade e vida instintual'” (Vol. XXII). In Edição Standard Brasileira das Obras Psicológicas Completas de Sigmund Freud. Rio de Janeiro, RJ: Imago. (Trabalho original publicado em 1933).

Freud, S. (2006). Além do princípio de prazer. In Obras Psicológicas de Sigmund Freud - Escritos sobre a Psicologia do Inconsciente vol. 2. Rio de Janeiro, RJ: Imago. (Trabalho original publicado em 1920).

Freud, S. (2007a). O eu e o id. In Obras Psicológicas de Sigmund Freud-Escritos sobre a Psicologia do Inconsciente, vol. 3. Rio de Janeiro, RJ: Imago. (Trabalho original publicado em 1923).

Freud, S. (2007b). O problema econômico do masoquismo. In Obras Psicológicas de Sigmund Freud - Escritos sobre a Psicologia do Inconsciente, vol. 3. Rio de Janeiro, RJ: Imago. (Trabalho original publicado em 1924).

Gerez-Ambertín, M. (2003). As vozes do Supereu - na clínica psicanalítica e no mal-estar na civilização. São Paulo, SP: Cultura Editores Associados/Caxias do Sul, RS: EDUCS.

Lacan, J. (1976). Clotûre aux Journées d'Etudes des Cartels. Lettres de l'Ecole Freudienne de Paris, 18, Paris, abril de 1976. (Trabalho original publicado em 1975).

Lacan, J. (1985a). O seminário. Livro 3. As psicoses. Rio de Janeiro, RJ: Jorge Zahar. (Trabalho original publicado em 1955-56).

Lacan, J. (1985b). O seminário. Livro 20. Mais ainda. Rio de Janeiro, RJ: Jorge Zahar. (Trabalho original publicado em 1972-73).

Lacan, J. (1992). O seminário. Livro 17. O avesso da psicanálise. Rio de Janeiro, RJ: Jorge Zahar. (Trabalho original publicado em 1969-70).

Lacan, J. (1995). O seminário. Livro 4. A relação de objeto. Rio de Janeiro, RJ: Jorge Zahar. (Trabalho original publicado em 1956-57).

Lacan, J. (1996a). O seminário. Livro 1. Os escritos técnicos de Freud. Rio de Janeiro, RJ: Jorge Zahar. (Trabalho original publicado em 1953-54).

Lacan, J. (1996b). O seminário. Livro 11. Os quatro conceitos fundamentais da 
psicanálise. Rio de Janeiro, RJ: Jorge Zahar. (Trabalho original publicado em 1964).

Lacan, J. (1998a). Escritos. Rio de Janeiro, RJ: Jorge Zahar. (Trabalho original publicado em 1966).

Lacan, J. (1998b). A direção do tratamento e os princípios do seu poder. In Escritos. Rio de Janeiro, RJ: Jorge Zahar. (Trabalho original publicado em 1958).

Lacan, J. (1998c). Subversão do sujeito e dialética do desejo no inconsciente freudiano. In Escritos. Rio de Janeiro, RJ: Jorge Zahar. (Trabalho original publicado em 1960).

Lacan, J. (2003a). Outros Escritos. Rio de Janeiro, RJ: Jorge Zahar.

Lacan, J. (2003b). O Aturdito. In Outros Escritos. Rio de Janeiro, RJ: Jorge Zahar. (Trabalho original publicado em 1972).

Lacan, J. (2003c). Televisão. In Outros Escritos. Rio de Janeiro, RJ: Jorge Zahar. (Trabalho original publicado em 1973).

Lacan, J. (2005a). O seminário. Livro 10. A angústia. Rio de Janeiro, RJ: Jorge Zahar. (Trabalho original publicado em 1962-63).

Lacan, J. (2005b). O triunfo da religião. Rio de Janeiro, RJ: Jorge Zahar. (Trabalho original publicado em 1974).

Lacan, J. (2007). O seminário. Livro 23. O Sinthoma. Rio de Janeiro, RJ: Jorge Zahar. (Trabalho original publicado em 1975-76).

Lacan, J. (2009). O seminário. Livro 18. De um discurso que não fosse semblante . Rio de Janeiro, RJ: Jorge Zahar. (Trabalho original publicado em 1971).

Lacan, J. (2012). O seminário. Livro 19, ...Ou Pior. Rio de Janeiro, RJ: Jorge Zahar. (Trabalho original publicado em 1971-72).

Pena, B. F. (2011, set.). O supereu e suas nuances de Freud a Lacan. Reverso, 33(62), 15-22.

\section{Resumos}

(About the superego as an antithetic to the phallus: The place of drugs in neurotic subejcts)

This article describes a clinical experience in a psychiatric inpatient unit for men diagnosed with drug addiction, which was analyzed based on the analyst's discourse (Lacan 1969-70/1992). The arrangement of the objet petit a reveals that the relationship with drugs is not always the cause of psychic suffering. One of the aspects of this clinic, in which neurotic subjects predominate, includes the drive to repeat failure, resulting in the meaningless. This is not related to drugs, but rather 


\section{ARTIGOS}

to the subject's modus operandi. Pointing out the antithesis between phallus and superego as the only instance that imposes jouissance, we establish the difference between drug abuse as a suspension of phallic jouissance, as proposed by Lacan (1975/1976), and compulsive repetition that exhausts the subject and results in failure.

Key words: Neurosis, phallus, superego, drug

(Du surmoi antithétique au phallus: la place de la drogue chez le sujet nevrótique)

Cet article est basé sur l'expérience clinique acquise dans une unité d'hospitalisation psychiatrique pour hommes atteints de toxicomanie. Cette expérience est pensée à partir de ce qui est extrait du discours de l'analyste (Lacan 1969-70/1992). L'agencement de l'objet petit a révèle que le rapport à la substance n'est pas toujours la cause de la souffrance psychique. L'un des aspects présents dans cette clinique, où prédominent les sujets névrosés, est la poussée à répéter l'échec, engendrant le non-sens. Une telle action ne concerne pas la relation avec la drogue, mais révèle le modus operandi du sujet. En soulignant l'antithèse entre phallus et surmoi, seule instance qu'impose la jouissance, on établit la différence entre l'usage de la drogue comme suspension de la jouissance phallique, comme l'indique Lacan (1975/1976) et la répétition compulsive qui épuise le sujet et réalise l'échec.

Mots clés: Névrose, phallus, surmoi, drogue

(Del superyó antitético al falo: el lugar de la droga en sujetos neuróticos)

Este artículo se basa en la experiencia clínica vivenciada en una unidad de hospitalización psiquiátrica para hombres diagnosticados con adicción a las drogas. Tal experiencia fue tomada de lo que se extrae del discurso del analista (Lacan 196970/1992). El agenciamiento del objeto a revela que la relación con la sustancia no siempre es la causa del sufrimiento psíquico. Uno de los aspectos presentes en esta clínica, en la que predominan los sujetos neuróticos, es el impulso por repetir el fracaso, engendrando lo sin sentido. Dicha acción no se relaciona a la droga, sino que revela el modus operandi del sujeto. Señalando la antitesis entre falo y superyó, como la única instancia que impone el goce, establecemos la diferencia entre el consumo de drogas como una suspensión del goce fálico, como lo indica Lacan (1975/1976), y la repetición compulsiva que agota al sujeto y lleva al fracaso.

Palabras-clave: Neurosis, falo, superyo, droga

Citação/Citation: Bezerra, D. S., \& Darriba, V. A. (2020, junho). Do supereu antitético ao falo: o lugar da droga em sujeitos neuróticos. Revista Latinoamericana de Psicopatologia Fundamental, 23(2), 198-220. http://dx.doi.org/10.1590/1415-4714.2020v23n2p198.4. 
Editora/Editor: Profa. Dra. Ana Maria G. R. Oda

Submetido/Submitted: 8.12.2019/ 12.8.2019 Revisado/Revised: $14.4 .2020 / 4.14 .2020$

Aceito/Acepted: $17.5 .2020 / 5.17 .2020$

Copyright: (C) 2009 Associação Universitária de Pesquisa em Psicopatologia Fundamental/ University Association for Research in Fundamental Psychopathology. Este é um artigo de livre acesso, que permite uso irrestrito, distribuição e reprodução em qualquer meio, desde que o autor e a fonte sejam citados / This is an open-access article, which permits unrestricted use, distribution, and reproduction in any medium, provided the original authors and sources are credited.

Financiamento/Funding: Este trabalho não recebeu apoio / This work received no funding.

Conflito de interesses/Conflict of interest: Os autores declaram que não há conflito de interesses. / The authors declare that there is no conflict of interest.

\section{Daniela Santos Bezerra}

Doutora em Pesquisa e Clínica em Psicanálise (2018) pelo PGPSA/UERJ - Universidade do Estado do Rio de Janeiro (Rio de Janeiro, RJ, Br); Psicanalista membro do Laço Analítico Escola de Psicanálise; Psicóloga da Secretaria de Estado de Saúde de Mato Grosso (Cuiabá, MT, Br) na Unidade 3 do CIAPS Adauto Botelho e na Coordenadoria de Promoção e Humanização da Saúde.

Coordenadoria de Promoção e Humanização da Saúde

Rua Julio Domingos de Campos "Seo Fiote", S/N, Bloco 5 - Centro Político Administrativo

78049-902 Cuiabá, MT, Br.

danielabezer@gmail.com

https.//orcid.0000-002-6947-0321

Vinicius ANCIÃes DARriba

Doutorado (2003) em Teoria Psicanalítica pela Universidade Federal do Rio de Janeiro - UFRJ (Rio de Janeiro, RJ, Br); Professor Associado do Instituto de Psicologia da Universidade do Estado do Rio de Janeiro - UERJ (Rio de Janeiro, RJ, Br); Vice-chefe do Departamento de Psicanálise. Membro do Programa de Pós-Graduação em Psicanálise. Coordenador do Instituto de Psicologia no Hospital Universitário Pedro Ernesto (Rio de Janeiro, RJ, Br).

Rua São Francisco Xavier, 524/10024, bloco B - Maracanã

20550-011 Rio de Janeiro, RJ, Br.

viniciusdarriba@gmail.com

https.//orcid.0000-0002-9986-6554

This is an open-access article, which permits unrestricted use, distribution, and reproduction in any medium for non-commercial purposes provided the original authors and sources are credited. 